\title{
Bird watching in China reveals bird distribution changes
}

\author{
LI XueYan ${ }^{1,2}$, LIANG Lu ${ }^{3}$, GONG Peng ${ }^{2,3^{*}}$, LIU Yang $^{4} \&$ LIANG FeiFei ${ }^{3}$ \\ ${ }^{1}$ College of Global Change and Earth System Science, Beijing Normal University, Beijing 100875, China; \\ ${ }^{2}$ Institute of Remote Sensing Application, Chinese Academy of Sciences; State Key Laboratory of Remote Sensing Science, Beijing Normal \\ University, Beijing 100101, China; \\ ${ }^{3}$ Center for Earth System Science, Tsinghua University, Beijing 100084, China; \\ ${ }^{4}$ Key Laboratory for Biodiversity Science and Ecological Engineering, Beijing Normal University, Beijing 100086, China
}

Received July 13, 2012; accepted July 27, 2012; published online September 16, 2012

Using China Bird Report (2003-2007) as data source in combination with descriptions about bird habitats, we built up the China Bird Watching Database. We also developed spherical GIS software "Global Analyst" to create the point-based database which contains accurate spatial-temporal information. The China Bird Watching Database can reflect the achievement of Chinese bird watchers and complement the basic knowledge of bird distribution. Now a total of 30936 records from 17 Orders, 70 Families and 1078 Species of 5 years are included in the database, representing over $80 \%$ of all bird species in China. Till 2007, the geographic coverage has encompassed all provincial level administrative districts in China, with the exception of Hong Kong and Taiwan. The China Bird Watching Database also recorded a group of species which are additions at national and provincial levels, including 14 species which are additions to the national checklist and 109 species which appeared outside their original distributions. Comparing the new records with their original distributions, we found the trend that species move to higher latitude and higher elevation regions and some species of waterfowls in Xinjiang Uygur Autonomous Region, including a suite of rare seabirds in the mainland China. The majority of bird watchers come from the Eastern Region of China, but their covering range is spreading northwest. At the same time, we appeal to adopting a suite of new technologies for observation, and building up sharing platform of bird watching data to capture the distribution dynamics of birds in China and provide a direct foundation for bird conservation.

bird watching database, bird distribution change, new records, Global Analyst crowdsourcing

Citation: $\quad$ Li X Y, Liang L, Gong P, et al. Bird watching in China reveals bird distribution changes. Chin Sci Bull, 2013, 58: 649-656, doi: 10.1007/s11434012-5458-7

Since bird is one of the most sensitive indicators of ecosystem health, both its habitat range and migration route could be affected by global climate change and the most direct impacts come from human activities and global warming [1]. Since recent years, the status and trend of bird distribution have drawn an increased attention in the field of global change. However, to date there have been no geographic distribution database of birds that is convenient for spatialtemporal analysis in China.

Nowadays, the widely-used knowledge of the distribution data of birds mainly comes from experts' experience and investigations. They often use provincial level adminis-

*Corresponding author (email: gong@irsa.ac.cn) trative district, natural conservations and ecoregions as basic unit to describe the distribution, such as "A Checklist on the Classification and Distribution of the Birds of China" [2] or "A Field Guide to the Birds of China" [3]. Some on-line database also used them as data sources, including the species information of China's bird network database (http:// www.birder.cn), China Animal Scientific Database (http:// www.zoology.csdb.cn) or the Site Record Database for Chinese Galliformes (SRDG) [4]. These databases can completely reflect the distribution of birds in China in relatively coarse unit, but without geographic location or time series that are critically needed for spatial-temporal analysis. At the same time, considering the negative effect of habitat degradation and fragmentation [5-7], these databases may 
fail to represent the true distribution of birds. In addition, there were also many local, regional or conservational field surveys [8-10], which have high accuracy but cannot reflect the overall habitat in the whole country due to their limitation in ranges.

Recently the bird watching records have caused ornithologists' attention. Records from long-term monitoring programs such as Breeding Bird Survey (http://www.pwrc. usgs.gov/BBS/), Christmas Bird Count (http://birds.audubon. org/christmas-bird-count) or BTO (http://www.bto.org/) have provided a large amount of first-hand materials for researchers. Recent studies have highlighted the impact of human activities [11], response of climate change [12], identification of biodiversity hotspots [13], development of natural conservations and evaluation of protective effect $[14,15]$. Bird watching data contains information about accurate coordinate or detailed description of occurrence in time which may play an important role in refining their distribution ranges and downscaling distribution units. In addition, these records also have such advantages as low cost, more information, easy to obtain, long time series, high accuracy and convenience for spatial- temporal analysis. To date, we still lack a published database which contains all bird species in mainland China with above advantages.

China Bird Report, the only journal publishing annual bird records from China, is a substantial and credible information source on the current distribution and conservation status of Chinese birds. Such a rich source of bird data has enabled all China Bird Report since 2005 to publish records of over 1000 species, representing about $80 \%$ of the China list [16]. Every record has been organized and checked by ornithologists to ensure its accuracy. Its detailed description of observation could help to enhance the quality of the database. Being the supplementary information of basic distribution data, these reports could help us to draw a completely and timely understanding of distribution change, especially for endangered species. More activities of bird watching could be encouraged by analyzing the distribution and source of these records. The quality and scientific value of bird watching data could be improved as well. Therefore, we initiated to establish the China Bird Watching Database using spherical GIS software "Global Analyst" (GA) [17]. We then compared the new records with their original distributions and made a preliminary analysis on the spatialtemporal characteristics of records and bird watchers.

We aimed to use the most complete bird watching records to build up a database with geographic coordination and lay a foundation for future accumulation of bird watching records. The purpose of this paper was to address the following questions: (1) what are the special characteristics and value of bird watching records as a new source of data? (2) how are the geographic pattern of new records distributed in comparison with their original ranges, and (3) how to improve the development of the China Bird Watching Database based on current data.

\section{Data}

\subsection{Data sources and the production methods}

The data source of this study is "China Bird Report" (20032007), published in 2004-2008, which recorded the information about species, date, location, number and observer in detail. Take the record about mute swan (Cygnus olor) in year 2005 as an example:

0066\# Mute Swan Cygnus olor

Shandong: Easily the largest count of the year was 83 at Yellow River Delta NR on 6 February [SK].

Sichuan: Five at Waqie, Hongyuan \& flying towards Zoige, on 4 December [SY].

Xinjiang: One at Ulungur Hu, Fuhai on 24 July [GJun].

(Abbreviated name of observer in square brackets)

Using topographic maps or databases with geocoding to spatialize such detailed bird watching records that cover the entire China will cost lots of time and energy, and may not attain satisfied accuracy. Actually, how to obtain accurate location of geographic names on different scales has been a bottleneck problem of many databases in the field of history, ecology and environment science. We adopted the Global Analyst software to solve the problem. Using Google Earth remote sensing images which have high resolution and timely update as base map, Global Analyst can support place name-querying and also provide abundant information about habitats and geographic ranges for mappers. The workflow of the China Bird Watching Database is as follows: (1) digitized the reports and defined format specifications of database. There are 13 fields of the attribute: index, order, family, Chinese name, English name, Latin name, year, month, day, province, place, number and description. (2) Extracted information of suitable habitat according to monographs $[3,18]$ of bird distribution and built a checklist including vegetation type, land-cover type and elevation of habitat. Then, bird name was used as the key to match its record to habitat information. (3) Searched occurrence places by Global Analyst and located them by visual interpretation on Google maps. Added attribute of species to the location and created a KML file with geographic coordination and other attributes. This results in one species corresponding to one KML file which included all reports in one year. In the end, all files were merged into the bird watching database. (4) Cross checked the data to ensure accuracies. Different people have different understandings about habitats, so it is difficult to avoid error in the process of data production. However, we grouped data makers after the completion of the initial database to find controversial places by cross checking, and modified these places based on additional information search and standardization to reduce error.

\subsection{Accuracy evaluation}

Errors can occur in the process of field observation, recording, editing and digitalizing. In general, the accuracy of the 
database is affected by three factors. First of all, to prevent from being tracked and poached according to bird reports, volunteers and editors will blur the detailed description about bird finding places during the submission and publishing stages. We can only relocate the occurrence place by referencing the suitable habitats, land-cover type and elevation. Secondly, it is difficult for volunteers to pinpoint their geographic positions in field survey, so they often use vague descriptions like "somewhere to somewhere" or "near somewhere". Such cases always happen in Qinghai, Sinkiang or Tibet region, the furthest distance between two locations among them is up to $300 \mathrm{~km}$ apart and the nearest could be a few dozen kilometers. This type of vague descriptions accounts for $4 \%$ of all records. We tried to improve the pinpoint accuracy by looking for suitable habitats around the place where the name was mentioned in the record. The third factor comes from the uncertainty of natural conservations because many observers only recorded the name of conservations instead of specific locations. This type of data accounts for $16 \%$ of all records. Located the finding place only by name will definitely affect the accuracy, especially in large conservation areas. We used the center of the conservation area as finding place in the end.

\subsection{Database update}

The China Bird Watching Database 2003-2007 serves a basis for further update. We extracted all names of bird watching places that appeared in the database, including information about latitude, longitude and elevation, and organized them to form a bird watching place database. Each name corresponded to one specific geographic location. For names that appeared in the database, we can use ArcGIS 9.3 software [19] to join the locations and attributes. For names that occurred for the first time, we can produce new KML files by the Global Analyst software and add them into bird watching place database. It will be much easier for data producers to update and enlarge the China Bird Watching Database, or assimilate other surveys by using this place name database.

\subsection{Characteristics of the China Bird Watching Database}

The China Bird Watching Database has several characteristics as a new type of bird occurrence data.

Using points to represent bird occurrence data. Representing the location of bird by point with 3D spherical coordinate and elevation could greatly enhance the locational accuracy. It is not only convenient for us to use Global Analyst to visualize the data, but also easy to do spherical analysis on large scales. Compared with the traditional two-dimensional method, Global Analyst has many advantages in research about bird migration and avian flu spreading [20].

Convenient for users to update and maintain the database. Different from static database, the China Bird Watching
Database can be updated dynamically and modified conveniently. Being the data source, the annual published China Bird Report guaranteed the time series of data. A long time series and high-accuracy distribution database on bird distribution can provide strong support for studies about the response of birds to climate change and human activities.

An open platform for crowd sourcing. The on-line version of Global Analyst could be used by a vast number of volunteers to update and maintain bird watching records. Bird watchers can open their own accounts on Global Analyst website (http://www.globalanalyst.cn/) to upload records or photographs after bird watching activities or discuss and communicate with others. The on-line database will solve the problem of data gathering fundamentally.

\section{Distribution of China bird watching records}

\subsection{Species composition}

There are 30936 records from 2003 to 2007 in the China Bird Watching Database, including 17 Orders, 70 Families and 1078 Species (Figure 1). In terms of globally-threatened species on the IUCN red list, the China Bird Watching Database includes four Critically-endangered species, 11 Endangered species, and 44 Vulnerable species (Birdlife International, 2008. http://www.birdlife.org/datazone), whilst also highlighting 27 species under Protection Class I [21]. The database covers all provincial level administrative districts except Hong Kong and Taiwan. Yunnan Province has the most abundant bird records, followed by Sichuan and Sinkiang. The three provincial level areas above account for more than $30 \%$ of all records in China.

\subsection{New species}

The China Bird Watching Database includes 14 species which are additions to the national checklist (Table 1). These new records occurred in five provincial level units which are either border on other countries (Yunnan, Sinkiang and Tibet) or are coastal areas (Tianjin and Hebei). Yunnan Province has most new species ( 7 species) followed by Hebei (3 species). Among these new species, some of their original ranges are actually distant from China, for instance, Franklin's Gull might be vagrant. For species whose original habitats are close to China, including some Passeriformes like Alexandrine Parakeet might be breeders in China.

\subsection{Changes of bird range}

From 2003 to 2007, there are 109 species that appeared outside of their original distributions in the China Bird Watching Database (Table S1). (1) Many species of waterfowls were found in Xinjiang Uygur Autonomous Region including some rare genus Anas such as Long-tailed Duck (Clangula hyemalis), Lesser White-fronted Goose (Anser erythropus), 


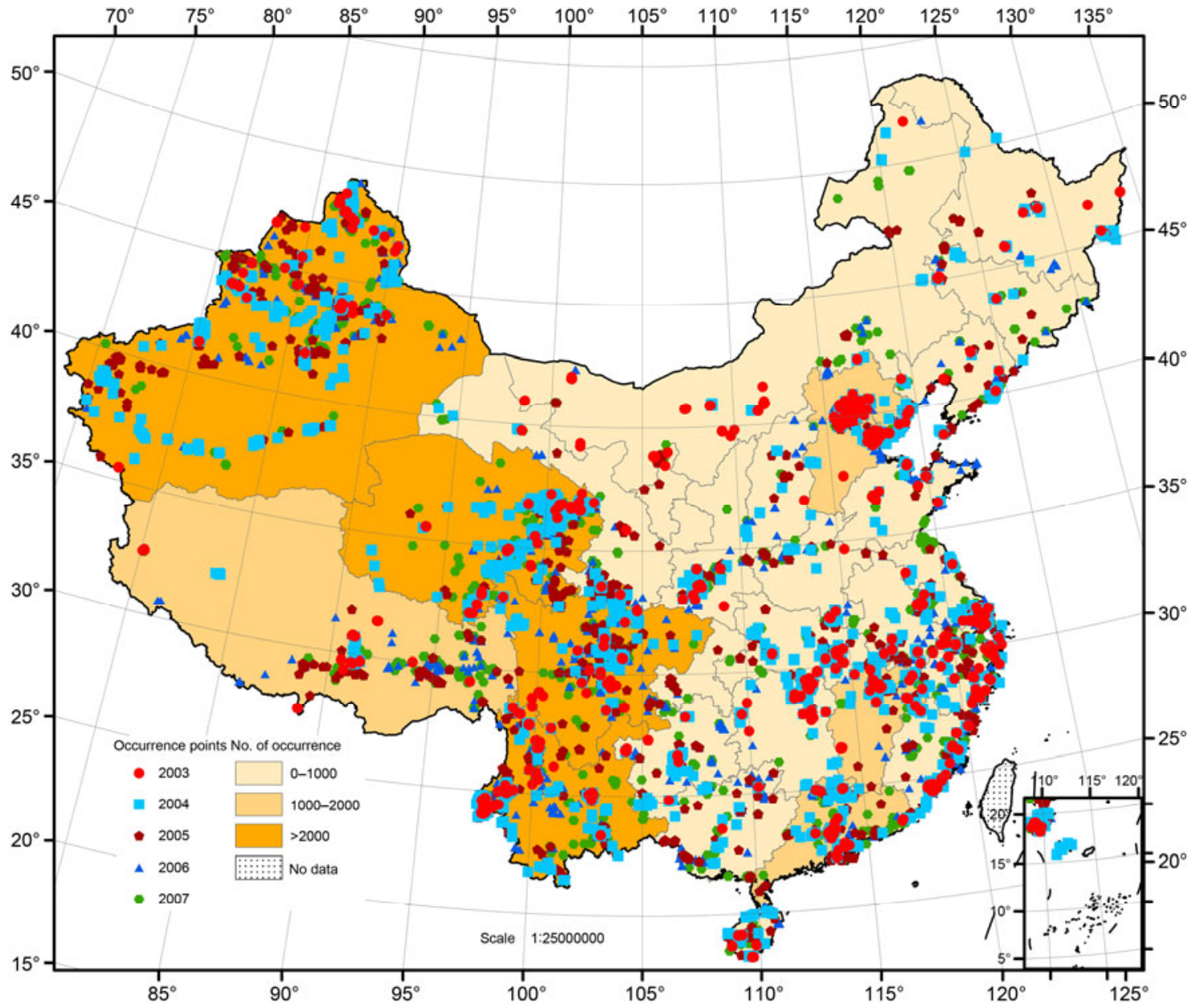

Figure 1 The distribution map of bird watching records from 2003 to 2007 in China Bird Watching Database.

Table 1 New records in the China Bird Watching Database from 2003 to 2007

\begin{tabular}{llll}
\hline \multicolumn{1}{c}{ Chinese name } & \multicolumn{1}{c}{ Latin name } & \multicolumn{1}{c}{ Date } & \multicolumn{1}{c}{ Place $^{\text {a) }}$} \\
\hline Alexandrine Parakeet & Psittacula eupatria & 12 Jan, 2004 & Lijiang and Ruili in Yunnan \\
European Greenfinch & Carduelis chloris & $16-20 \mathrm{Aug}, 2003$ & Yining, Kuitun to Tacheng in Xinjiang \\
Franklin's Gull & Larus pipixcan & $18 \mathrm{Sep}, 2004$ & Coastal areas in Tanggu, Tianjin \\
Spot-winged Starling & Saroglossa spiloptera & $22,23 \mathrm{Nov}, 2004$ & Ruili, Yunnan \\
Wire-tailed Swallow & Hirundo smuthii & 10 Jan, 2004 & Ruili Shengtai Park, China-Burma border in Wanding, \\
Blue-rumped Parrot & Psittinus cyanurus & $4 \mathrm{May}, 2005$ & Zhongmian river in Yunnan \\
Dark-rumped Swift & Apus acuticauda & $3 \mathrm{Nov}, 2005$ & Gaoligongshan, Yunnan \\
Himalayan Bulbul & Pycnonotus leucogenys & 28 Dec, 2005 & Rikaza, Xizang \\
Hume's Whitethroat & Sylvia althaea & $3 \mathrm{Aug}, 2005$ & west of Kashi, Sinkiang \\
European Golden Plover & Pluvialis apricaria & 28, 30, 31 Sept, 2006 & Dapuhe in Changli, Hebei \\
Asian Openbill & Anastomus oscitans & 3 Oct, 2006 & Erhai west lake in Dali, Yunnan \\
Long-billed Thrush & Zoothera monticola & 4 Feb, 2007; 6 Mar, 2007 & Moli Tropical Forest, Ruili, Yunnan \\
Tickell's Thrush & Turdus unicolor & 30 Jun, 2007; 1 Jul, 2007 & Zhangmu, Xizang \\
Red-breasted Flycatcher & Ficedula parva & 19 May, 2007 & Laoyujian in Laoting, Hebei \\
Nonggang Babbler & Stachyris nonggangensis & 21 Feb, 2007 & Nonggang NR in Longzhou, Guangxi \\
\hline
\end{tabular}

a) NR, Nature Reserve. 
Greater Scaup (Aythya marila), and some coastal species like Little Curlew (Numenius minutus), Red-necked Stint (Calidris ruficollis), Long-toed Stint (Calidris subminuta), Greater Painted Snipe (Rostratula benghalensis), Common Ringed Pliver (Charadrius hiaticula), Eastern Cattle Egret (Bubulcus coromandus) and Mew Gull (Larus canus). (2) There is a trend for birds moving to higher latitude and higher elevation regions, including Falcated Duck (Anas falcata), Pied Kingfisher (Ceryle rudis), Grey-headed Prarkeet (Psittacula finschii), Brown Crake (Amaurornis skool), Brown-chested Jungle Flycatcher (Rhinmyias brummeatus), Light-vented Bulbul(Pycnonotus taivanus), White- winged Redstart (Phoenicurus erythrogastrus), and some rare raptors in Sinkiang Uygur Autonomous Region. (3) Our database also recorded some unusual seabirds, including Slender-billed Gull (Chroicocephalus genei), Little Gull (Hydrocoloeus minutus), Lesser Frigatebird (Fregata ariel), Black-legged Kittieake (Rissa tridactyla), Lesser Crested Tern (Thalasseus bengalensis), Chinese Crested Tern (Thalasseus bernsteini), Black-naped Tern (Sterna sumatrana), Masked Booby (Sula dactylatra), White Tern (Gygis alba), and Parasitic Jaeger (Stercorarius parasiticus). Finally we compared the occurrence points with their original ranges in A Field Guide to the Birds of China (provincial

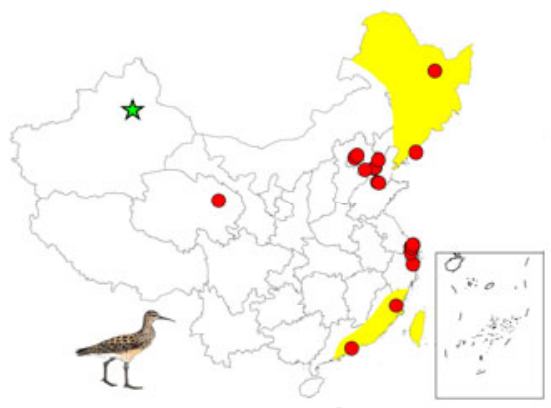

Little Curlew (Numenius minutus)

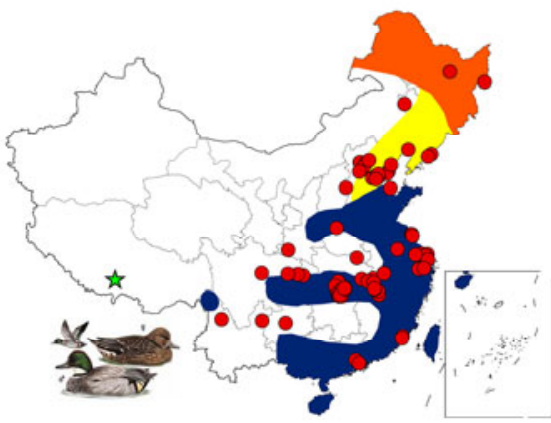

Falcated Duck (Anas falcata)

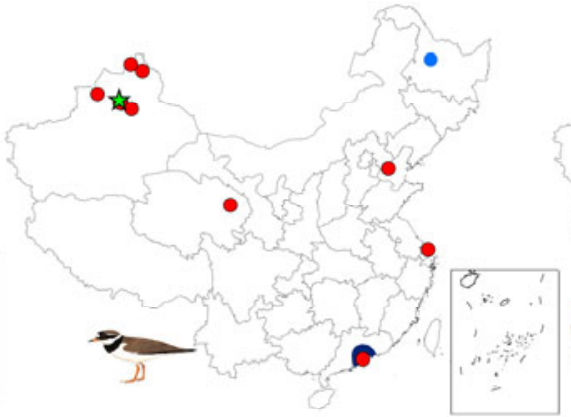

Common Ringed Pliver (Charadrius hiaticula)

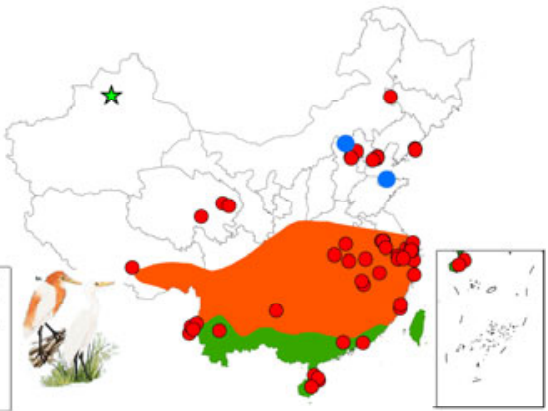

Eastern Cattle Egret (Bubulcus ibis)

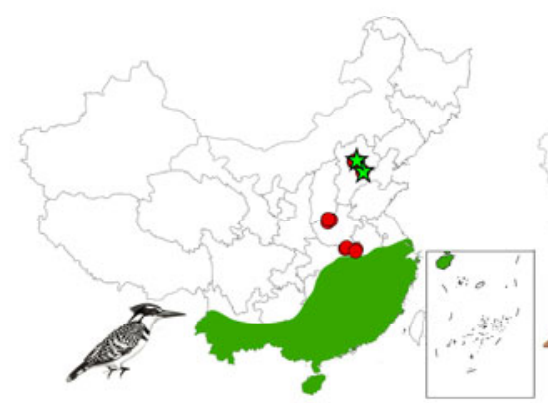

Pied Kingfisher (Ceryle rudis)

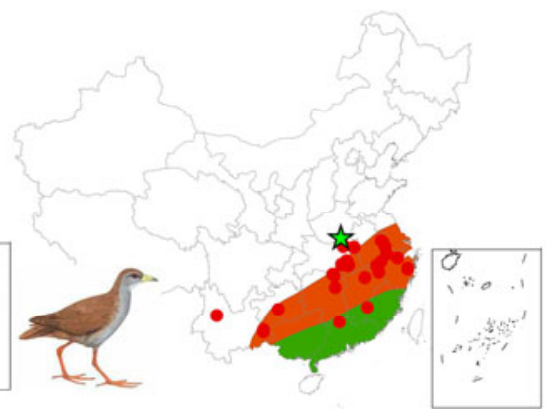

Brown Crake (Amaurornis akool)

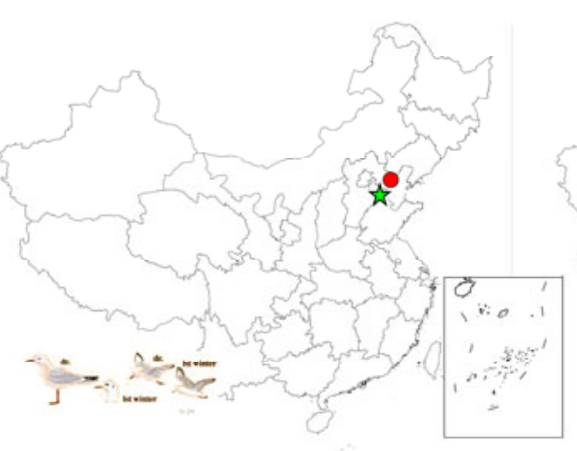

Slender-billed Gull (Larus genei)

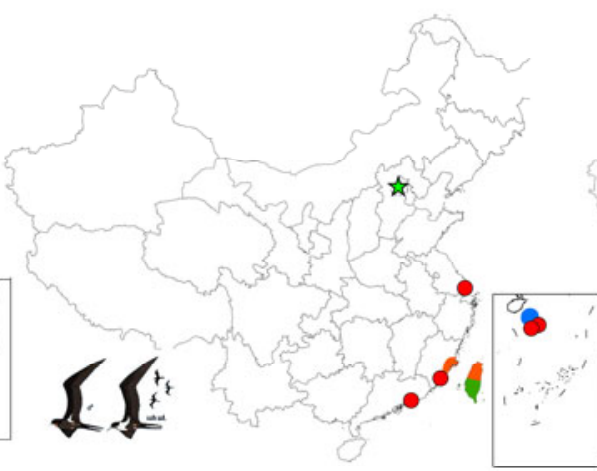

Lesser Frigatebird (Fregata ariel)

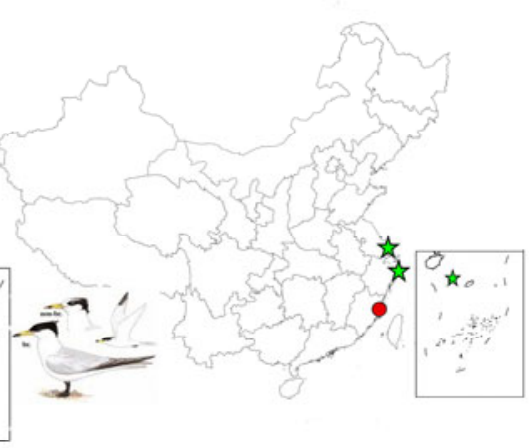

Chinese Crested Tern (Thalasseus bernsteini)

The Plates
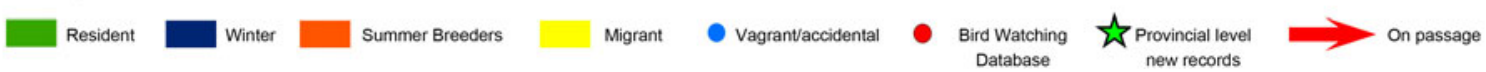

Figure 2 Part of the distribution maps of provincial level new records in the China Bird Watching Database. Scale is 1:25000000 and the original ranges and figures were digitalized according to A Field Guide to the Birds of China. 
level new records are colored in green, Figure 2) by spatial overlay analysis.

\subsection{The spatial-temporal distribution of occurrence points}

We counted the total number of bird watchers in each provincial level administrative district from 2003 to 2007 (Figure 3). The geographic pattern of bird watchers is very uneven and economically developed provinces often have more bird records. Beijing ranks first by bird watchers number; there are more than 50 people per year, followed by Guangdong, Shanghai and Zhejiang. There are no volunteers in Inner Mongolia, Gansu, Ningxia Hui Autonomous Region, Shaanxi, Qinghai, Tibet and Chongqing. From the view of interannual variation, Yunnan, Sichuan, Xinjiang, Qinghai, Beijing and Hebei have relatively large number of records and their growth is stable, and the numbers fluctuate more in regions that have fewer bird watchers.

\section{Discussion}

Bird watching activities have a long history of more than a hundred years, since American ornithologist Frank M.
Chapman appealed for "using counting instead of hunting" and came up with the original idea of the earliest bird monitoring program in the world-Christmas Bird Count (CBC) [22] in the late 19th century. There are many long-term bird surveys in Europe that have numerous participators. Bird watching activities started relatively late in China. Although in recent years the number of volunteers and organizations has experienced a rapid growth, the popularity of bird watching activities is still not large enough. From the aspect of data compensation of database, the majorities of bird watchers are professionals and they concentrate in economically developed provinces. The quantity, typicality and representativeness of records need to be improved too. From the aspect of range changes, it is impossible to avoid omissions only based on records provided by volunteers. Additionally, the problem of resampling because of high concern on some species and data bias due to uneven distribution of bird watchers also caused many troubles to the application of bird watching records. For example, Beijing is not a traditional hot spot of waterfowls because of its developed economy and large population. However, $7.3 \%$ of all records came from Beijing and they were concentrated in Miyun Reservoir, Huairou Reservoir, Changping Reservoir and Wild Duck Lake in Yanqing. How to overcome the subjectivity and make the distribution more realistic are big

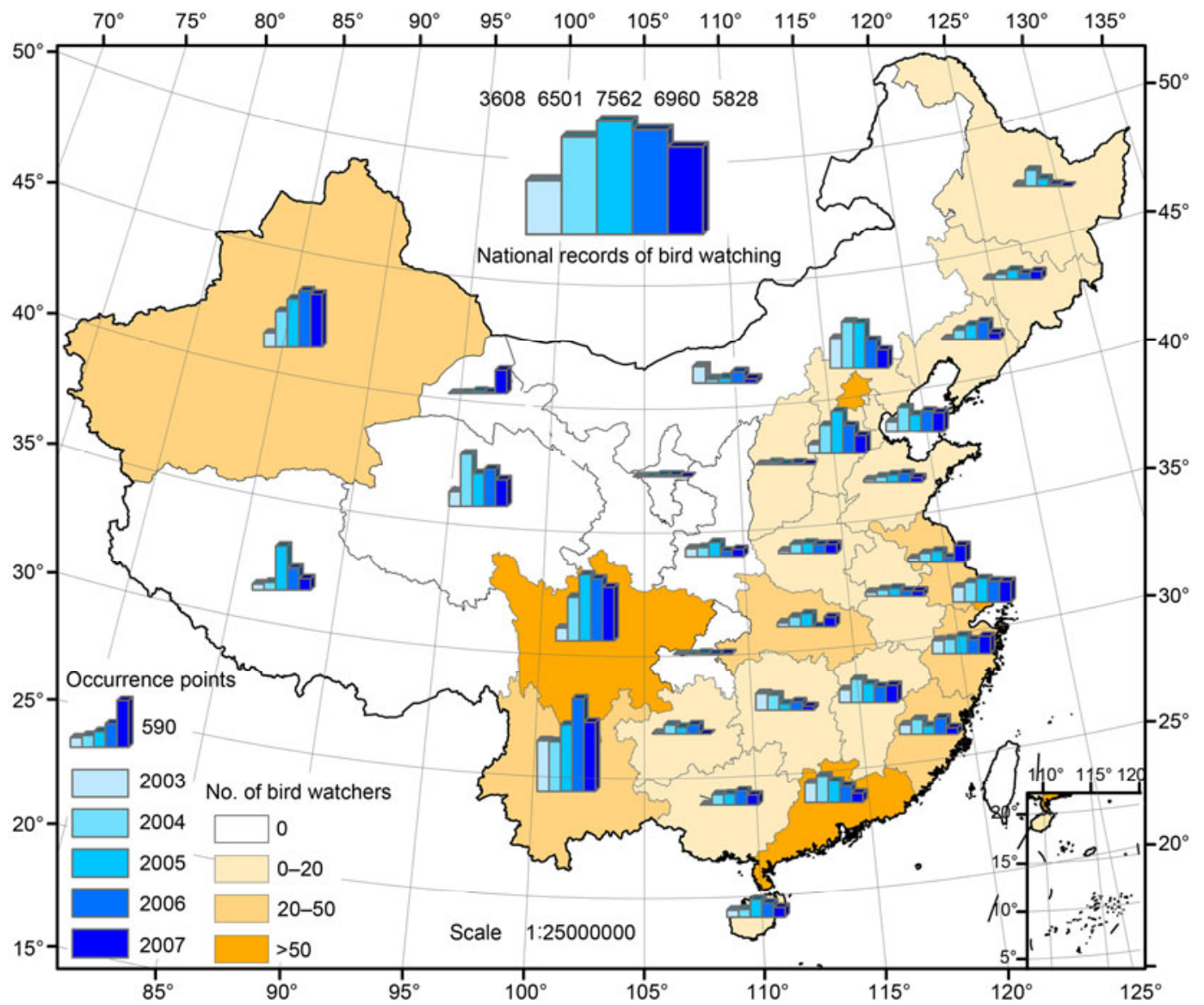

Figure 3 The distribution map of birdwatchers by provinces. 
questions facing by observers and organizers of bird watching activities. We have several suggestions based on successful cases in foreign countries and experience about gathering, producing and sharing data in this study.

(1) Using grid point arrangement and wireless sensor network for observation [23]. Considering the large area and uneven population distribution of China, it is hard to carry out systematic sampling and monitoring, especially in regions with small population and rugged environment. Adopt audio and video sensors to detect, recognize, count and locate birds [24], wireless sensor network could be a feasible solution for information collection because it can be placed in any environment, remote controlled without disturbance and get real-time data in long-time monitoring [25].

(2) Build up a sharing platform of bird watching data gathering. The platform could provide functions about data production, exhibition and integration. Records or photographs could be submitted to the on-line platform by cell phones or laptops. Besides bird watching, bird banding and survey data from State Forestry Bureau and other relevant departments, or international organizations could be added for as reference and supplement. The Bird watching database could also provide convenience for communication between observers to reduce double-sampling and fill gaps. The Global Analyst software we adopted in this study could meet all requirements mentioned above, which had played an important role in the development of the China's Wetland Database as well [26].

(3) Improve the representativeness of database by including other data sources. We will enrich the data source in the future construction of the China Bird Watching Database, including special investigations such as the China Coastal Waterbird Census Report [27] which has been developed for six years and contained 13 regions, and The Middle and Lower Yangtze Water Birds Survey Report, or national network of protection [28] to enrich the bird watching database and enhance its comprehensiveness and representativeness.

The decade of 2011-2020 is the international decade of biodiversity [29], it is necessary and possible for China to build up a group of platforms of long-term bird monitoring in order to capture their status and dynamic trends more completely. This would allow improved understanding on range shift of birds, their population dynamics and finally better prediction on the change trends of birds in China. At the same time, this work will provide direct evidence for research on bird biodiversity in China, and promote the development of more effective protection measures.

This work was supported by the Major Program of the National Natural Science Foundation of China (30590370), the National High-tech Research and Development Program of China (2009AA122000) and The China Conservation Fund of Hong Kong Bird Watching Society. The authors would like to thank the following members who took part in the work of literature organization and database construction, Li FeiFei and Xue XiaoJuan from Beijing Normal University, Fu XinYu, Jiao Tong, Guo ChunLei, Wang Yao and Hu LuanYun from Beijing Forest University. We also thank Yu Liang from Beijing Xiuying Environmental Information Technology Development Limited-liability Company to provide technical support in the development of Global Analyst software, and the guidance of Professor Zhengwang Zhang from Beijing Normal University.

1 Jetz W, Wilcove D S, Dobson A P. Projected impacts of climate and land-use change on the global diversity of birds. PLoS Biol, 2007, 5: e157

2 Zheng G M. A Checklist on the Classification and Distribution of the Birds of China (in Chinese). Beijing: Science Press, 2005

3 MacKinnon J R, Phillipps K, He F. A Field Guide to the Birds of China (in Chinese). Changsha: Hunan Education Press, 2000

4 Zhang C A, Ding C Q. The site record database for Chinese galliformes and its application (in Chinese). Chin J Zoo, 2007, 42: 73-78

5 Andren $\mathrm{H}$. Effects of habitat fragmentation on birds and mammals in landscapes with different proportions of suitable habitat: A review. Oikos, 1994: 355-366

6 Fahrig L. Effects of habitat fragmentation on biodiversity. Annu Rev Ecol Evol Syst, 2003: 487-515

7 Zheng Y M, Zhang H Y, Niu Z G, et al. Protection efficacy of national wetland reserves in China. Chin Sci Bull, 2012, 57: 1116-1134

8 Bao X, Zhang J, Qu Z, et al. Preliminary Investigation on the bird community in summer at Lalu wetland, Lhasa (in Chinese). Chin $\mathbf{J}$ Zoo, 2005, 40: 86-89

9 Zhang X F, Ba M T, Zhang K Y. Investigation of the winterbirds in dongzhai national mature reserve for birds (in Chinese). J Henan Agric Univ, 2002, 36: 334-340

10 Barter M, Lei G, Cao L. Waterbird Survey of the Middle and Lower Yangtze River Floodplain (Feb 2005) (in Chinese). Beijing: China Forest Bureau Publishing Company, 2006

11 Valiela I, Martinetto P. Changes in bird abundance in eastern North America: urban sprawl and global footprint? Biosci, 2007, 57: 360-370

12 Crick H Q P. The impact of climate change on birds. Ibis, 2004, 146: 48-56

13 Buchanan G M, Donald P F, Fishpool L D C, et al. An assessment of land cover and threats in Important Bird Areas in Africa. Bird Conserv Int, 2009, 19: 49-61

14 Godet L, Devictor V, Jiguet F. Estimating relative population size included within protected areas. Biodivers Conserv, 2007, 16: 2587-2598

15 Devictor V, Godet L, Julliard R, et al. Can common species benefit from protected areas? Biol Conserv, 2007, 139: 29-36

16 Society C O. China Bird Report 2007 (in Chinese). Beijing: China Ornithological Society, 2008

17 Gong P, Zhao Y C, Yu L, et al. Development of an integrated software platform for global mapping and analysis (in Chinese). Geomatic World, 2011, 9: 34-37

18 Sibley C G, Monroe B L. Distribution and Taxonomy of Birds of the World. New Haven: Yale University Press, 1990

19 Esri I. ArcGIS 9.3. Environmental Systems Research Institute, Redlands, 2008

20 Liang L, Xu B, Chen Y L, et al. Combining spatial-temporal and phylogenetic analysis approaches for improved understanding on global H5N1 transmission. PLoS One, 2010, 5: e13575

21 Zheng G M, Wang Q S. China Red Data Book of Endangered Animals (Aves) (in Chinese). Beijing: Science Press, 1998

22 Dunn E H, Francis C M, Blancher P J, et al. Enhancing the scientific value of the Christmas Bird Count. Auk, 2005, 122: 338-346

23 Shen S Q, Gong P, Cheng X, et al. Sound-based remote sensing of terrestrial animals: Localization and error analysis. J Remote Sens, 2011, 15: 1257-1281

24 Gong P. Progress in recent environmental applications of wireless sensor networks. J Remote Sens, 2010, 14: 387-395

25 Gong P. Wireless sensor network as a new ground remote sensing technology for environmental monitoring. J Remote Sens, 2007, 11: $545-551$ 
26 Niu Z G, Zhang H Y, Gong P. More protection for China's wetlands. Nature, 2011, 471: 305

27 China Coastal Waterbird Census Team. China Coastal Waterbird Census Report (1.2008-12.2009) (in Chinese). Hong Kong: Bird Watching Society, 2011
28 Committee A P M W C. Asia-Pacific migratory waterbird conservation strategy: 2001-2005. Wetlands International-Asia Pacific. Kuala Lumpur, 2001

29 Gong P. Review of Global Change Research-global Change and Biodiversity (in Chinese). Beijing: Higher Education Press, 2011

Open Access This article is distributed under the terms of the Creative Commons Attribution License which permits any use, distribution, and reproduction in any medium, provided the original author(s) and source are credited.

\section{Supporting Information}

Table S1 The provincial level new records in the China Bird Watching Database from 2003 to 2007

The supporting information is available online at csb.scichina.com and www.springerlink.com. The supporting materials are published as submitted, without typesetting or editing. The responsibility for scientific accuracy and content remains entirely with the authors. 